\title{
Small Hive Beetle (Aethina
}

\section{tumida) Contributions}

\section{to Colony Losses}

James D. Ellis

\section{Introduction}

Small hive beetles (Aethina tumida) are members of the coleopteran family Nitidulidae and are native to sub-Saharan Africa (Lundie, 1940; Schmolke, 1974; Neumann and Ellis, 2008). In their native range, small hive beetles typically inhabit colonies of African races, or subspecies, of Western honey bees (Apis mellifera). In 1996, small hive beetles were found in colonies of European races of honey bees in the United States (Figure 1). Since that time, they have been found in Australia (Neumann and Ellis, 2008), where they have established populations, and in a few other countries where they do not seem to have established populations [such as Portugal (Neumann and Ellis, 2008) and Canada (Lounsberry et al., 2010).

Techniques in molecular genetics have provided a way to understand beetle presence in and dispersion through areas in which they are introduced. In North America, small hive beetles (SHB) have at least two distinct mitochondrial DNA haplotypes, thus initiating some discussion of the number of separate introductions into and their subsequent spread within the United States (Evans et al., 2003; Lounsberry et al., 2010). Furthermore, genetic markers have been improved, allowing a similar discussion on the global scale (Evans et al., 2007). Lounsberry et al. (2010) examined genetic variation in adult beetles collected from the United States, Australia, Canada, and Africa. They demonstrated that beetles in Canada were from at least two separate introductions, one from the United States and the other from Australia. SHB in North America and Australia appear to have different African origins (Lounsberry et al., 2010).

A number of good reviews on the biology, behavior, ecology, and control of SHB exist (Hood, 2000, 2004; Neumann and Elzen, 2004; Neumann and Ellis, 2008; Ellis 2005a,b,c; Ellis and Hepburn, 2006). In this chapter, I focus primarily on how SHB impact honey bee colonies and contribute to colony losses in the United States, though it is important to appreciate the biology of SHB to understand how they impact honey bee colonies specifically. I include within each section of this chapter a brief discussion of researchable topics that remain poorly understood for SHB.
CHAPTER

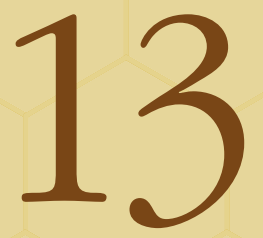

\begin{abstract}
Small hive beetles (Aethina tumida) can kill honey bee colonies and impact colony health and productivity significantly. They typically inhabit colonies of African races or
\end{abstract} subspecies of Western honey bees (Apis mellifera), probably identifying the host colony by a suite of olfactory cues. Small hive beetles depend on bee colonies as their primary host. Molecular techniques have helped us understand the introduction, presence, and spread of the beetles in North America. The majority of losses occur in the southern United States, particularly the Southeast The beetles appear to be a more regional than global pest. The largest threat to the bee colony posed by this beetle are the beetle larvae that feed on honey, pollen, and bee brood. The focus of this chapter is on how small hive beetles impact honey bee colonies and contribute to colony losses in the United States. I emphasize the biology, researchable topics that remain poorly understood, particularly in the area of control (chemical, cultural, biological, genetic), and the need for further work. Control of small hive beetles seems to be best accomplished by attacking all beetle life stages simultaneously and maintaining bee colonies in a populous and healthy state. 


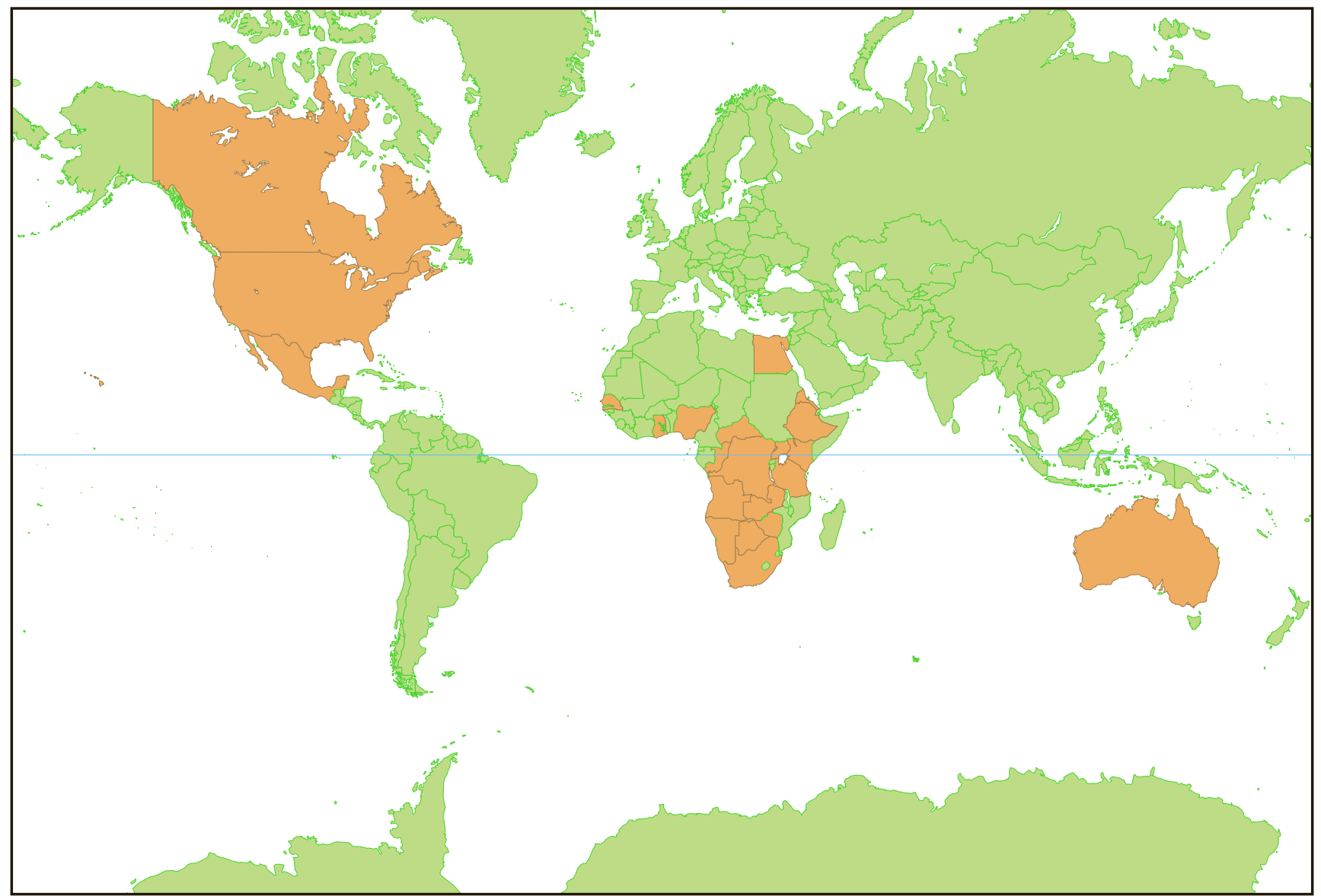

Figure 1. The global distribution of small hive beetles (modified from Ellis and Munn, 2005; Neumann and Ellis, 2008). Shaded countries are where the beetle occurs, though their exact distribution within a given country may be unknown. For example, small hive beetles are in Australia so the entire country is shaded. However, the beetles are not distributed across the entire country.
This inclusion hopefully will demonstrate the need for further work on this significant honey bee pest.

\section{Small Hive Beetle Life Cycle}

SHB pupate in the soil around bee colonies (Lundie, 1940; Schmolke, 1974). Upon emerging from the ground, adult beetles (Figure 2) search for colonies, probably identifying the host colony by a suite of olfactory cues. Though SHB will feed and reproduce on fruit (Ellis et al., 2002b; Buchholz et al., 2008; Arbogast et al., 2009) - a behavior similar to that of other nitidulid beetles - they likely are dependent on bee colonies as their primary host. Some have suggested that SHB may reproduce on fruit in vivo (Arbogast et al., 2009; Arbogast et al., 2010) but this certainly is a topic that needs further investigation. If SHB are able to reproduce on fruit and do so readily, their populations could be sustained in areas where honey bees are not present.

Investigators have shown that SHB fly before or just after dusk (Elzen et al., 1999) and that odors from adult bees and various hive products (honey, pollen) are attractive to flying SHB (Elzen et al., 1999; Suazo et al., 2003; Torto et al., 2005; Torto et al., 2007a). Some authors have suggested that SHB may find host colonies by detecting honey bee alarm pheromones produced either by the bees themselves or by a yeast (Kodamaea ohmeri) carried by the beetles that produces components of the bee's alarm pheromone when deposited on pollen reserves in the hive (Torto et al., 2007b). 


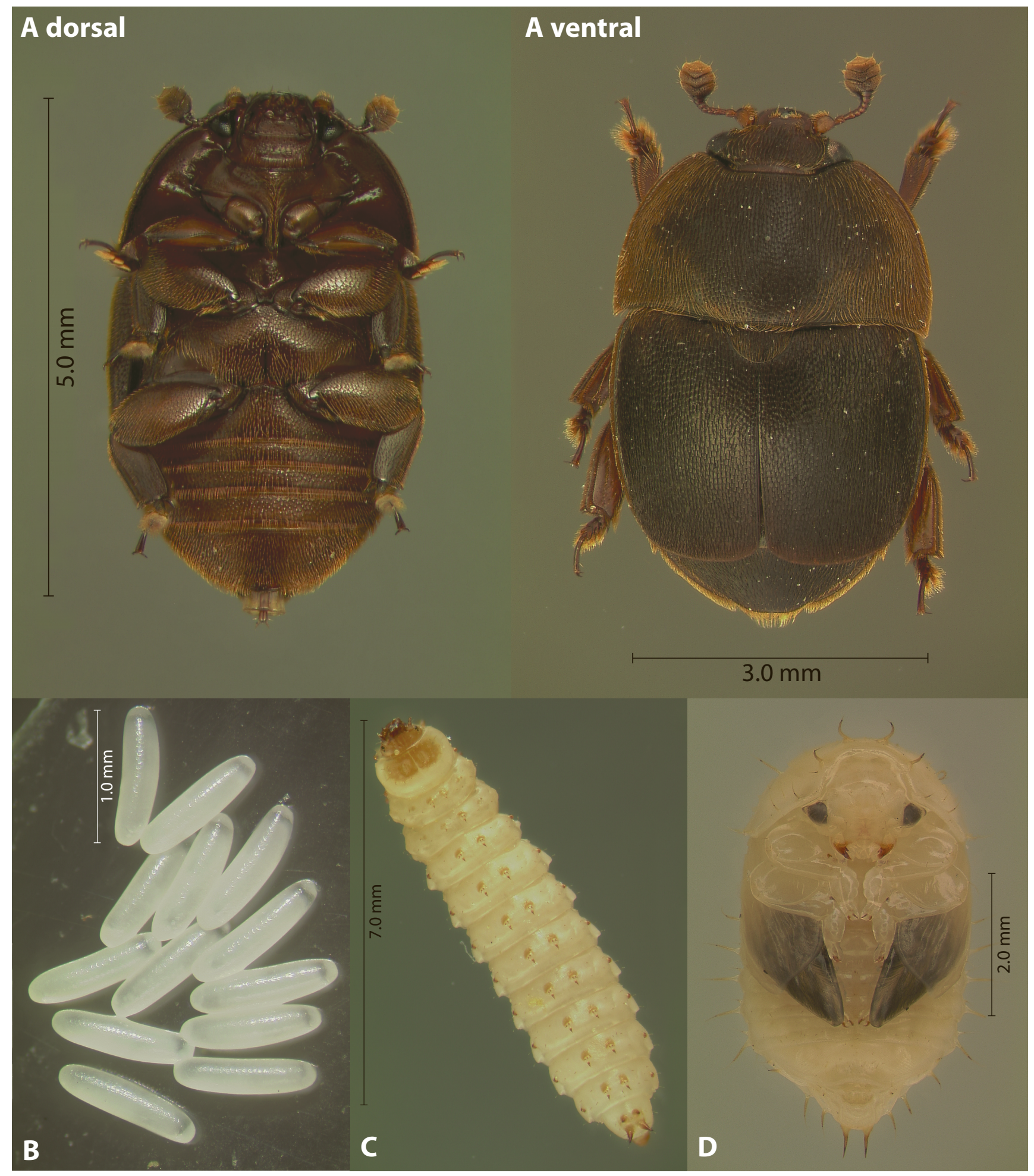

Figure 2. The life cycle of the small hive beetle. A. adult beetle (dorsal and ventral view), B. beetle eggs, C. beetle larvae (dorsal view), D. beetle pupae (ventral view). (Photos courtesy of the University of Florida .) 
Upon locating a colony, adult beetles are met with some resistance by the bees as they try to enter the nest. Once inside, the beetles hide in cracks and crevices around the periphery of the nest where they escape bee aggression (Ellis, 2005c). It remains unknown if beetles actively seek these sites as part of their normal behavior in colonies (i.e., they "want" to be in these sites) or if they find the sites passively as they try to escape bee aggression (i.e., they are "forced" into these sites by the bees). Regardless, honey bees station guards around the cracks/crevices where SHB hide. The sites are called "confinement sites" because the beetles are confined by the bees at these locations (Ellis et al., 2004b). By confining SHB, the guard bees limit beetle access to the brood combs where there is an ample supply of honey, pollen, and brood on which adult beetles reproduce. SHB do not starve while confined because they are able to solicit food trophallactically from their bee captors (Ellis et al., 2002a). The beetles accomplish this by using their antennae to rub the bees' mandibles, thus inducing the bees to regurgitate; the beetles then feed on the regurgitated substance.

Mating behavior of SHB (including whether female beetles mate once or multiple times) is not understood well, but beetles do not appear to be sexually mature until about one week post-emergence from the soil (Lundie, 1940; Schmolke, 1974). If able to escape confinement and reproduce, female beetles oviposit directly onto food sources such as pollen (Lundie, 1940) or on developing bee brood (Ellis et al., 2003a). Alternatively, female beetles may deposit irregular masses of eggs (Figure 2B) in crevices or cavities away from the bees; the ovipositors are long and flexible, and are perfectly designed to lay eggs in tiny and concealed places. A female beetle may lay 1,000 eggs in her lifetime. The majority of these eggs hatch within 3 days (Lundie, 1940); however, some eggs remain viable and hatch after 5 days. Humidity appears to be a crucial factor influencing hatch rates because small hive beetle eggs are prone to desiccation if exposed to circulating air and a relative humidity below 50\% (Jeff Pettis, personal communication, unpublished data). Though beetle reproduction is not clearly visible in all hives, low-level, cryptic reproduction occurs in most colonies in which beetles are present (Spiewok and Neumann, 2006a).

Newly hatched beetle larvae (Figure 2C) immediately begin feeding on whatever food source is available including honey, pollen, and bee brood (Lundie, 1940; Schmolke, 1974), yet they have demonstrated a preference for bee brood (Elzen et al., 1999). Maturation time for larvae is generally 10 to 14 days although some may feed longer than a month (Lundie, 1940; Ellis et al., 2002b). Once the larvae finish feeding, a "wandering" phase is initiated where they leave the food source and migrate out of the colony to find suitable soil in which to pupate (Lundie, 1940). It is believed that most larvae do this at night.

Larvae in the wandering stage may wander some distance from the hive to find suitable soil in which to pupate, though most pupate within $90 \mathrm{~cm}$ ( $\sim 3$ feet) of the hive (Pettis and Shimanuki, 2000). Nearly 80\% of the larvae burrow down into the soil less than $10 \mathrm{~cm}$ ( 4 inches) from the soil surface but not generally more than $20 \mathrm{~cm}(\sim 8$ inches; Pettis and Shimanuki, 2000). They pupate (Figure 2D) best in moist soil (Ellis et al., 2004c). Once larvae cease burrowing, they construct a smooth-walled, earthen cell in which they pupate. The period of time spent in the ground pupating can vary greatly, depending on factors such as soil temperature (de Guzman and Frake, 2007); however, the majority of adults emerge 
from the soil in 3 to 4 weeks (Lundie, 1940). Upon adult emergence, the entire life cycle begins again. The turnover rate from egg to adult can be as little as 4 to 6 weeks; consequently, there may be as many as six generations in a 12-month period under moderate United States climatic conditions.

Much about SHB biology remains unknown. For example, no one is sure how far they can fly when searching for a host colony or if soil $\mathrm{pH}$ affects pupation success. Furthermore, we know very little about how confinement behavior is initiated within a colony, be it from the beetles themselves or from a sub-cohort of bees who "imprison" small, invading arthropods. Finally, the trophallactic relationship between SHB and guard honey bees remains unclear. Though we know SHB are fed honey (Ellis et al., 2002a), we do not know if they also pass food or other substances to their bee captors.

\section{Colony Damage Typically Attributed to Small Hive Beetles}

SHB can kill honey bee colonies. Though they are not responsible for universal, widespread colony losses as are other stressors (such as Colony Collapse Disorder, disease, or poor nutrition), they can plague beekeeping operations in areas where they are present. In their native range of subSaharan Africa, SHB regularly occur in honey bee colonies but typically do not damage strong, healthy hives (Lundie, 1940; Schmolke, 1974), even though low-level, cryptic beetle reproduction occurs (Spiewok and Neumann, 2006a). That said, African subspecies of honey bees are not immune completely to SHB as they can kill colonies, cause them to abscond, and may hurt other areas of colony productivity (Ellis et al., 2003b). Overall damage attributable to SHB in colonies south of the Sahara likely is minimal compared to the damage beetles can cause in European bee colonies that are in the beetle's introduced range. Why this is the case remains unknown.

It is possible that African races of honey bees are more aggressive toward SHB than are European races of bees (Elzen et al., 2001). That said, European bees also confine SHB (Ellis, 2005c) and bite/attack the beetles whenever possible. Regardless, more research should be conducted to determine how African races of honey bees tolerate small hive beetle invasion when European bees often do not.

In the United States and Australia, European bee colonies often succumb to SHB damage. Typically the process follows a characteristic pattern:

1. Adult beetle invasion into colonies

2. Population buildup of adult beetles

3. Reproduction of adult beetles

4. Significant damage to brood, pollen, and honey stores by feeding beetle larvae (Figure 3)

5. Exodus of larvae from the colony

6. Beetle pupation in the soil

7. Beetle emergence as adults and subsequent reinfestation of colonies (Ellis and Ellis, 2008). 
Figure 3. Two views of honey bee comb damaged by feeding small hive beetle larvae. Notice how the comb is "slimed" due to the fermentation of honey. (Photo courtesy of University of Florida.)
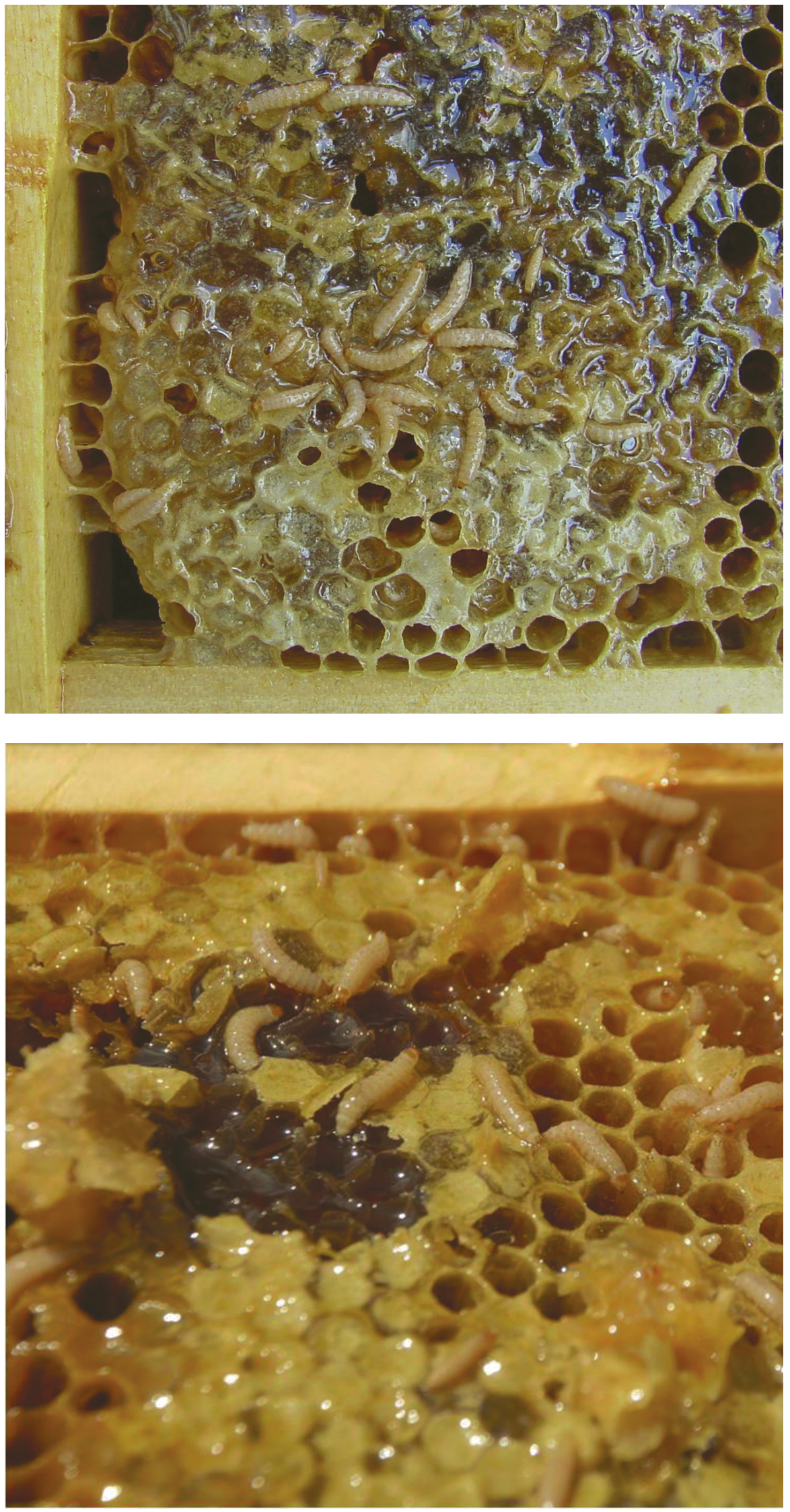
Though this pattern is somewhat predictable, the amount of time it takes to complete this cycle, which ultimately leads to colony loss, is unpredictable, as are the triggers that turn ordinary beetle inhabitance of colonies into damaging beetle presence. For example, SHB tend to occupy many/most colonies in an area where they are present. Yet, only a certain percentage of infested colonies ultimately succumb to beetle pressures. Furthermore, beetle damage in colonies does not appear completely related to beetle density within colonies (Delaplane et al., 2010). As such, step two in the typical pattern of colony loss (population buildup of beetles) does not appear critical if other conditions/stressors are present in the colony.

Likely, many colony losses attributable to SHB were initiated by other stressors. For example, queenless colonies, nucleus or other small colonies, and colonies stressed with parasites/pathogens all appear hypersensitive to SHB and associated depredation. To that end, SHB increasingly are considered a secondary pest of bee colonies, much like the greater (Galleria mellonella L.) and lesser (Achroia grisella Fabricius) wax moths. On the other hand, it is possible that not all stressors predispose colonies to SHB damage. Varroa mite (Varroa destructor Anderson and Trueman) infestations, for example, may not be linked directly to small hive beetle damage as investigators failed to correlate colony varroa mite populations with colony susceptibility to SHB (Delaplane et al., 2010). Regardless, colonies appear to be vulnerable to SHB more when they are stressed in other ways first. Though not always easy to investigate, synergisms between SHB and other colony stressors should be investigated further.

SHB may not be problematic only to honey bee colonies. In controlled studies, SHB have been shown to infest and cause significant damage to managed bumble bee colonies. Ambrose et al. (2000) and Stanghellini et al. (2000) found that commercial Bombus impatiens colonies artificially infested with SHB suffered significantly from beetle damage, with the beetles being able to complete a full life cycle within the colonies. Spiewok and Neumann (2006b) found that commercial B. impatiens colonies maintained close $(\sim 100$ or $\sim 500 \mathrm{~m})$ to beetle-infested honey bee colonies became infested with SHB, which reproduced successfully. Hoffman et al. (2008) placed four commercial B. impatiens colonies and four honey bee colonies in a closed greenhouse and released 1,000 SHB. All colonies of both bee types were invaded by the beetles, which oviposited in the colonies and showed no apparent preference to honey bee over bumble bee colonies. Interestingly, the stingless bee Trigona carbonaria has been shown to host SHB but can avoid damage attributable to the beetles by mummifying them alive. The bees do this by coating the beetles with a mixture of mud, wax, and resin (Greco et al., 2010).

\section{Other Effects of Small Hive Beetles on Colonies}

SHB do not only cause colony collapse or death but they can affect honey bee colonies in other ways. First, there is a fermentation of hive products (particularly honey) associated with the feeding beetle larvae (Lundie, 1940; Schomolke, 1974). This likely occurs due to specific yeasts associated with the SHB. Affected honey can "bubble" out of the combs, resulting in a frothy mess inside the hive. Honey damaged by SHB is rendered foul and unfit for human or bee consumption.

Second, honey bee colonies heavily infested with adult SHB may abscond or completely abandon the nest (Ellis et al., 2003b). Admittedly, 
the number of adult beetles to elicit this behavior in European honey bee colonies likely must be high ( $>1,000$ beetle adults/colony). However, colonies of African bees may abscond in response to lower beetle populations because African races of bees are prone to absconding anyway (Hepburn and Radloff, 1998). Although adult beetles are known to promote absconding behavior, it remains unclear if the presence of beetle larvae (particularly high populations of beetle larvae) can do the same.

As predicted (Ellis and Hepburn, 2006), SHB have been shown to transmit pathogens within (and possibly between) honey bee colonies mechanically (Eyer et al., 2009ab; Schäfer et al., 2010). This is the third way beetles can affect colonies without killing them directly. The bodies of SHB are covered with hair and other anatomical features that permit them to acquire bee pathogens. Beetle movement within diseased colonies and subsequent relocation to healthy colonies is a possible method of mechanical transmission of pathogens between colonies; although this has not been shown with certainly (Koch's Postulates must be satisfied first). SHB are known to harbor Sacbrood Virus (Eyer et al., 2009a), Deformed Wing Virus (Eyer et al., 2009b), and Paenabacillus larvae, the American foulbrood bacterium (Schäfer et al., 2010). Furthermore, it is possible, though untested, that SHB can acquire pathogens from bees trophallactically when confined (Ellis et al., 2002a). Regardless, beetle contributions to the movement of bee pathogens within and between honey bee colonies (mechanical transmission) must be investigated further as should their role as possible vectors of bee pathogens (i.e., the pathogen reproduces within the small hive beetle, making the beetle a true vector).

There is a fourth cost to honey bee colonies when hosting SHB: the cost of mounting an immune response to the beetle. The two primary immune responses of bee colonies to SHB include confinement behavior (Ellis, 2005c) and adult bee hygienic behavior toward beetle eggs/young larvae (Ellis et al., 2003a, 2003d, 2004a; Neumann and Härtel, 2004; Ellis and Delaplane, 2008; de Guzman et al., 2008). Confinement behavior involves honey bees being diverted from jobs they would do ordinarily to guarding confined SHB. Ellis et al. (2003c) showed that European and African races of honey bees are 19 to 21 days old, respectively, when they begin guarding confinement sites. At this age, worker bees should begin foraging for colony resources. As such, increased populations of SHB within colonies may lead to a reduction in foraging activity in affected colonies (Ellis et al., 2003b).

Additionally, SHB can oviposit directly into brood cells (Ellis et al., 2003a), a behavior that elicits hygienic responses from adult worker bees. The bees are able to detect eggs (Ellis et al., 2003d, 2004a; Ellis and Delaplane, 2008; de Guzman et al., 2008) and young larvae (Lundie, 1940; Schomolke, 1974; Neumann and Härtel, 2004) present in the brood and remove the affected brood and beetle eggs/larvae. Although this trait may benefit colonies overall, expending energy to remove young bees that would otherwise contribute to the workforce seems costly to the colony.

A final effect of SHB is that their presence may make colonies susceptible to invasion by other beetles. "Small" hive beetles-so named to distinguish them from a variety of scarab beetles invading bee colonies (i.e., "large" hive beetles, Swart et al. 2001)—are not the only nitidulid beetles known to invade honey bee colonies. Cychramus luteus (Neumann and Ritter, 2004), Glischrochilus fasciatus, Lobiopa insularis, and Epuraea corticina (Ellis et al., 2008) all have been found in bee colonies, though 
they are presumed innocuous to honey bees. Regarding G. fasciatus, $L$. insularis, and E. corticina, all three have been found in honey bee colonies also hosting SHB (Ellis et al., 2008). It is possible, though untested, that the presence of SHB in bee colonies has opened an ecological niche for other invading nitidulid beetles (beetles never before documented in honey bee colonies prior to the occurrence of SHB) via their fermentation of hive products.

\section{Small Hive Beetle Contributions to Colony Losses}

It has been difficult to assess the overall impact of SHB on bee colonies in the United States. In surveys of colony losses, fewer than $1 \%$ (vanEngelsdorp et al., 2008) and 1.9\% of beekeeper respondents (vanEngelsdorp et al., 2010) reported losing colonies to SHB during the 2007-2008 and 2008-2009 beekeeping seasons in the United States. The same surveys showed that the losses attributable to SHB were insignificant compared to losses due to colony starvation, queen loss, weather, mites, Colony Collapse Disorder, Nosema, management, and other colony issues.

Most losses attributable to SHB occur in the southern United States, particularly the Southeast where beetle populations are highest and the climate is conducive to beetle reproduction. Their presence in Australia is relatively localized as well (Neumann and Ellis, 2008). Consequently, SHB seem to play a minor role in overall colony losses in areas where they are introduced, although under certain circumstances their presence can impact colony health and productivity significantly.

\section{Small Hive Beetle Control}

Since the introduction of SHB into the United States, little progress toward developing chemical control methods has been made. Two pesticides are available, permethrin and coumaphos. Permethrin as an active ingredient is used as a ground drench and kills beetle larvae and pupae in the soil around infected colonies. As an in-hive control, the organophosphate coumaphos is embedded into a plastic strip that is placed on the bottom board of a colony. The strip is placed under a piece of cardboard where the beetles can hide, thus exposing them to the active ingredient. Neither product is very efficacious, though some beetle control is possible with both (Ellis, 2005a,b).

Because of the lack of quality chemical control options, more attention has focused on integrated pest management (IPM) using cultural, biological, and genetic controls. Cultural/mechanical controls result from a change in practice with the intention of limiting, but not eradicating, a pest. Practices such as removing honey, bits of comb and cappings from around the honey house will minimize foodstuffs to which SHB may be attracted (Hood, 2000, 2004; Ellis, 2005a,b). It is also important to extract supers of honey quickly to reduce the damage that adults beetles and larvae do to standing, unprotected honeycombs. Reducing the relative humidity to $50 \%$ in honey houses and other places where honey is stored inhibits SHB eggs from hatching (Jeff Pettis, personal communication). In the apiary, eliminate, requeen, or strengthen weak colonies to reduce colony stress and to make the colony better able to deal with the beetles. Avoid other conditions that might lead to colony stress such as brood diseases, mite problems, wax moth activity, failing queens, excessive swarming, and over-supering. 
Multiple, moderately effective in-hive trapping devices have been developed for SHB control. These traps often are filled with an attractant (usually apple cider vinegar) and/or a killing agent (mineral oil, vegetable oil, etc.) and typically capture adult beetles. Some traps, such as the Hood Beetle Trap (Hood and Miller, 2003; Hood, 2006; Nolan and Hood, 2008), are placed within a frame while others, such as the West Beetle Trap (West, 2004), go under colonies, thus providing a place for beetles to hide.

Other control measures are being developed. For example, the yeast Kodamaea obmeri, when mixed with pollen, produces volatiles that attract other SHB to weakened colonies (Torto et al., 2007b). Researchers are taking advantage of this relationship and are developing traps using the yeast mixed with pollen as bait for adult SHB (Noland and Hood, 2008). Second, multiple species of soil-dwelling nematodes have demonstrated activity against pupating SHB (Cabanillas and Elzen, 2006; Ellis et al., 2010; Shapiro-Ilan et al., 2010). Two species in particular that have shown promise as controls include Heterorhabditis indica and Steinernema riobrave (Ellis et al., 2010). Additionally, some fungal species have shown activity against pupating SHB, though the efficacy of fungi as biological controls remains questionable (Ellis et al., 2004d; Richards et al., 2005; Muerrle et al., 2006). Finally, researchers have shown that some honey bee colonies are able to detect and remove brood that has been oviposited on by SHB (Ellis et al., 2003d, 2004a; Ellis and Delaplane, 2008; de Guzman et al., 2008). This behavior, called hygienic behavior, possibly can be selected for in-breeding programs and may help reduce SHB problems.

SHB control probably is best accomplished by attacking all beetle life stages simultaneously. For example, one can use in-hive traps for adult beetles, nematodes for wandering larvae and pupal beetles, and hygienic breeds of bees for beetle eggs and young larvae. That said, the best defense to date against SHB is maintaining colonies in a populous and healthy state. Without question, the control of SHB is a research topic that still needs considerable further attention.

\section{Conclusion}

In conclusion, SHB likely do not contribute significantly to global losses of honey bee colonies, though they can be an important regional menace. That may change over time as the beetle disperses into areas where it is not indigenous. More research needs to be conducted to determine more subtle effects of their presence in bee colonies and to develop control measures for this pest. 